\title{
Mycobacterium avium: an Emerging Pathogen for Dog Breeds with Hereditary Immunodeficiencies
}

\author{
Giovanni Ghielmetti ${ }^{1} \cdot$ Urs Giger $^{2}$ \\ Published online: 18 August 2020 \\ (C) The Author(s) 2020
}

\begin{abstract}
Purpose of Review Among the non-tuberculous mycobacteria (NTM), Mycobacterium avium complex (MAC) is the leading cause of pulmonary disease in humans. Innate and acquired immunodeficiencies have been associated with an increased host susceptibility to NTM infections. The underlying mechanisms predisposing humans and dogs to MAC infections are being elucidated.

Recent Findings Although MAC infection is infrequently diagnosed in dogs, a strong breed predisposition particularly for Miniature Schnauzer and Basset Hound dogs is evident. A recessively inherited defect of the adaptor protein CARD9 has recently been documented to be responsible for the increased susceptibility to MAC in the Miniature Schnauzer breed.

Summary Given the zoonotic potential of a MAC-infected dog particularly to immunocompromised human patients, diseased dogs pose a public health risk. While not a reportable disease, treatment of systemic mycobacteriosis is generally not effective and discouraged in dogs. The collaborative efforts by microbiologists, veterinary clinicians, dog breeders, primary care physicians, and infectious disease specialists applying the One Health approach are therefore crucial for the best management and prevention of MAC infection.
\end{abstract}

Keywords Mycobacterium avium $\cdot$ Dog $\cdot$ Non-tuberculous mycobacteria $\cdot$ Precision medicine $\cdot$ Cutaneous and disseminated mycobacteriosis

\section{Introduction}

Mycobacterial infections are caused by bacteria that belong to the family Mycobacteriaceae, order Actinomycetales. The genus Mycobacterium recently underwent important taxonomic change proposals, and the redistribution of 150 Mycobacterium species into five new genera has become a controversial issue among microbiologists, clinicians, and researchers [1, 2•]. Besides the emended genus Mycobacterium, the four newly proposed genera Mycobacteroides, Mycolicibacter, Mycolicibacterium, and

This article is part of the Topical Collection on Bacteriology

Giovanni Ghielmetti

giovanni.ghielmetti@vetbakt.uzh.ch

1 Institute for Food Safety and Hygiene, Section of Veterinary Bacteriology, University of Zurich, Winterthurerstrasse 270, 8057 Zurich, Switzerland

2 Clinic for Small Animal Internal Medicine, Vetsuisse Faculty, University of Zurich, Winterthurerstrasse 260,

8057 Zürich, Switzerland
Mycolicibacillus are still debated regarding the phylogeny and taxonomy of large bacterial clades. On one hand, the necessity of an up-to-date core genome sequence-based phylogeny and taxonomy of a large heterogeneous group, such as the genus Mycobacterium, contributes to a more precise understanding of bacterial rise and evolution [1]. On the other hand, such drastic changes have led to confusions and potentially impede the exchange of information between researchers, microbiologists, and clinicians and, thereby, to patients and pet owners $[2 \cdot 3]$. Moreover, some of the newly proposed genera or families comprise pathogens causing various notifiable diseases worldwide; therefore, misinterpretation of microbiology test results may occur. Few species mentioned, hereafter, have been recently published according to the newly proposed nomenclature, e.g., Mycolicibacterium smegmatis for Mycobacterium smegmatis. Therefore, for the sake of clarity, mycobacterial species in the present manuscript will be preceded by " $M$." referring to Mycobacterium, regardless of the recently proposed nomenclature.

Although extremely heterogeneous in their host affinity and pathogenic potential, mycobacteria share important morphological similarities. Mycobacteria are aerobic bacteria, 
non-spore-forming, and non-motile. Because of the high concentration of mycolic acid in their cell walls, mycobacteria are difficult to stain with common techniques, such as the Gram stain. However, once mycobacteria are heated in the presence of carbol-fuchsin, this stain can penetrate their lipid-rich cell wall. And while other non-acid-fast bacteria are commonly decolorized by acid alcohol, mycobacteria are able to retain the Ziehl-Neelsen dye [4]. For this reason, mycobacteria are also commonly called acid-fast bacteria, which is, however, not unique to this genus. Other medical-relevant genera belonging to the Actinomycetales, such as Nocardia and Rhodococcus, are also acid-fast and could be erroneously misidentified as mycobacteria by Ziehl-Neelsen stain.

The recent enormous advances in molecular genetic techniques allowed readily the sequencing of single or multiple housekeeping genes followed by whole genome sequencing of any bacteria. Microbial isolates can nowadays be identified with the highest accuracy expediently and relatively inexpensively which led to the definitive description and partial reclassification of a myriad of new species and genera as well as precision medicine. Alone during the past decade, more than 50 new species of mycobacteria were published [5].

Although whole genome sequencing of bacteria is being progressively implemented in diagnostic laboratories, it is not (yet) feasible for daily routine diagnostic purposes. Currently, reverse hybridization-based line-probe commercial kit assays are commonly used for mycobacterial identification of clinical isolates. In addition, matrix-assisted laser desorption ionization-time of flight mass spectrometry (MALDI-TOF MS) has proven to be a rapid and accurate tool in the diagnostic workflow of larger laboratories [6, 7]. Nevertheless, accuracy of the MALDI-TOF MS-based species identification remains inferior to genome sequencing [5].

Mycobacterial diseases are clinicopathologically divided into two main groups: tuberculosis and mycobacteriosis.

Tuberculosis (TB) in humans and different animal species is caused by the members of the Mycobacterium tuberculosis complex (MTBC), which are obligate pathogens showing marked host predilections. The MTBC includes currently the human-adapted species M. tuberculosis and M. africanum; the animal-adapted M. bovis, M. caprae, M. microti, M. pinnipedii, $M$. orygis, the "dassie bacillus"; and the more recently discovered M. mungi, the "chimpanzee bacillus", and M. suricattae [8]. In addition, $M$. canettii is also considered a member of the MTBC based on nucleotide identity, albeit opportunistic infections in humans [8]. The members of the MTBC are believed to be host-adapted and, with the exception of $M$. canettii which has a putative environmental reservoir, they can be found in contaminated environments. Dogs infected with $M$. tuberculosis, M. bovis, and M. microti have been rarely documented worldwide [9-11]. Therefore, dogs are considered a spillover host for MTBC pathogens, meaning that there is no maintenance of the pathogen within the canine population without continued exposure to a primary host and reservoir [12].

The modality of infection with MTBC members depends on the specific pathogen (M. tuberculosis, M. bovis, $M$. microti) and the geographical and socio-economic environment of dogs. The infection with the human-adapted M. tuberculosis is spread almost exclusively by airborne transmission, and the lungs are its primary target. The mycobacteria can disseminate, resulting in various other clinical manifestations depending on the affected organ. To the contrary, M. bovis and M. microti are believed to be transmitted to dogs via contaminated animal products. Independently from the infecting species, canine TB is characterized by a long incubation period (months to years) resulting in asymptomatic carriers and chronic slowly progressive disease that can be often detected solely by indirect diagnostic test methods.

In most countries, contrary to human and livestock species, collection and submission of samples for mycobacterial testing from a dog when suspecting TB is not mandatory, but rather initiated based upon good clinical judgment by a clinician and dog owner. Moreover, there are no regulations on managing dogs after documentation of MTBC, but due to the high zoonotic risk, euthanasia is generally recommended. Furthermore, the prolonged administration of antituberculosis agents can be highly toxic to dogs.

Mycobacteriosis is caused by opportunistic pathogenic non-tuberculous mycobacteria (NTM). The NTM are ubiquitous, e.g., in soil and water, and healthy humans and animals are considered fairly resistant to mycobacteriosis. Among NTM, two species are recognized as true pathogens for humans, namely M. marinum and M. ulcerans [13]. Nevertheless, more than 60 species of NTM are known to be opportunistic pathogenic to humans and other mammals, and infections with these emerging pathogens are now more common than tuberculosis in industrialized countries [5, 14, 15]. Geographical differences concerning the prevalence of different NTM have been described in veterinary and human medicine, e.g., higher prevalence of feline leprosy caused by a number of mycobacteria, namely, M. lepraemurium, M. visibile, and novel mycobacterial species such as Mycobacterium sp. Tarwin, in cats is seen in temperate maritime climates [16]. Similarly, the buruli ulcer, a chronic skin disease in humans caused by $M$. ulcerans, occurs mostly in tropical and subtropical regions [17]. The most common NTM species encountered in humans with lung infections are members of the Mycobacterium avium complex (MAC), M. abscessus, and M. kansasii depending on geographical regions [18]. Numerous NTM have been reported in dogs causing a variety of clinical manifestations, including skin, respiratory, gastrointestinal, and disseminated disease.

To date, the virulence of specific mycobacterial species and their strains for a particular host and whether a transmission 
from domestic or wild animals to humans and vice versa can occur remain largely unknown. Moreover, the reason why ubiquitous mycobacteria are able to cause serious lifethreatening illness to some individuals while being innocuous to other individuals of the same species is now being elucidated. In human and veterinary medicine, underlying hereditary and acquired immunodeficiency disorders have recently been discovered to cause predispositions specifically to mycobacteriosis and may guide selection of treatment including triple drug therapy. In dogs, infections due to NTM are sporadically reported worldwide, but the exact source of the mycobacteria remains in most cases unknown. Epidemiological data concerning NTM infections of dogs are missing. Moreover, time-consuming and laborious detection methods and a low disease awareness could be responsible for a potentially large number of undiagnosed cases. Indeed some dogs in Miniature Schnauzer breed have a common genetic predisposition to NTM which has been documented from clinicopathological signs to the molecular genetic defect. A rapid genotyping approach currently permits precise detection of diseased dogs and asymptomatic carriers, facilitating specific management and prevention in future generations.

\section{Mycobacterium tuberculosis}

Mycobacterium tuberculosis is the primary cause of TB in humans worldwide, with the exception of few specific geographical regions (e.g., M. africanum in West Africa), and can also occur in dogs after prolonged close contact with TB patients [19, 20]. Mycobacterium tuberculosis can be experimentally transmitted by close contact between animals, and, consequently, infected dogs could act as reservoir for human infections [21]. Pulmonary, cutaneous, and disseminated disease manifestations have been reported in dogs [11, 22-25]. In most cases, the infection develops with granulomatous inflammation localized mainly to the lungs, skin, kidneys, bone marrow, and/ or digestive system and associated lymph nodes [21].

\section{Mycobacterium bovis}

Mycobacterium bovis is the pathogenic agent causing TB with the broadest known host spectrum. Infection chains in numerous domestic and wild mammal and the resulting transmissions to humans have recently led to the term "zoonotic TB" by the World Health Organization (WHO) [26]. Furthermore, the number of $M$. bovis, and to a lesser extent by the closely related $M$. caprae, infections in humans might well be underestimated because of a lack of diagnostic surveillance programs [26]. Nevertheless, $M$. bovis infections are rare in dogs and, as in humans, mostly associated with consumption of raw milk or contaminated byproducts from affected ruminants [27-29]. Clinical findings of infected dogs vary from respiratory signs and cutaneous lesions to gastrointestinal signs accompanied by fever, inappetence, and weight loss.
Gray wolves (Canis lupus), ancestors of the domestic dog, are susceptible to natural infections with $M$. bovis and $M$. caprae [30, 31] and may be infected by their preys such as domestic and wild ruminants. Interestingly, their TB seems to be mild and self-limiting. Since diseased wild ungulates are an easy prey of wolves, they may play a role in controlling TB in wild ruminant populations [31]. Domestic dogs may be more prone to tuberculosis because of their restricted genetic pool and associated increased inbreeding practices.

\section{Non-tuberculous Mycobacteria}

Non-tuberculous mycobacteria (NTM) are commonly divided into rapidly growing mycobacteria which usually grow in subculture within 1 week and those that require longer incubation to form visible colonies and are termed slowly growing mycobacteria such as the members of the MAC [15]. In dogs, a large variety of rapid- and slow-growing mycobacteria can cause mycobacterial granulomas of the cutis and subcutis, and the resulting lesions are clinically mostly indistinguishable $[32 \bullet \bullet$.

The Mycobacterium sp. causing canine leproid granulomas has yet to be isolated in culture and sequenced. Canine leproid granuloma is a nodular dermatosis affecting the cutis and subcutis of the dog, usually located on the head, especially on the dorsal fold of the ears. Although the geographical distribution of the disease is probably wider, dogs with leprosy have been mostly described from Australia, where it is the predominant mycobacterial disease of dogs, Brazil and the USA, particularly in the Central Valley of California [32••, 33, 34].

Mycobacterium ulcerans, the environmental pathogen responsible for the Buruli ulcer disease, can infect both humans and animals and remains a major public health problem [17, 35]. Although the ecology and transmission of this pathogen remain mostly unexplained, recent research and phylogenetic analyses suggest a common environmental source of contamination for humans and animals, including domestic dogs [35]. Painless nodules, papules, necrotic ulcers, plaques, and/or edema of the cutis and subcutis are common clinical features of this infectious disease in humans and dogs [36]. In addition, similar chronic non-healing cutaneous and subcutaneous lesions have been described in dogs with rapidly growing (e.g., M. smegmatis [37], M. goodii [37, 38], M. fortuitum [37, 39], and M. chelonae-abscessus [40]) and slowly growing mycobacteria, (e.g., MAC, M. nebraskense [41]).

Apart from cutaneous and subcutaneous infections and the subsequently discussed MAC infections, clinical manifestations due to NTM infections in dogs have been rarely reported, e.g., pulmonary disease due to M. fortuitum [42-44], mastitis and persistent pleural effusion caused by M. kansasii [45, 46], or disseminated disease characterized by lameness and ataxia with M. smegmatis [47] and M. genavense [48]. 


\section{Mycobacterium avium Complex}

The MAC, encompasses a heterogeneous group of slowgrowing NTM that are opportunistic pathogenic for humans and animals. Historically, the complex consisted of two species: M. avium and $M$. intracellulare. This classification was based upon the pathogenity to birds, being $M$. avium pathogenic and M. intracellulare experimentally avirulent to fowls [49••]. With the major diagnostic improvements and heightened awareness among clinicians, new MAC species were described including M. arosiense, M. bouchedurhonense, M. chimaera, $M$. colombiense, M. ituriense, M. lepraemurium, M. marseillense, M. paraintracellulare, M. scrofulaceum, M. timonense, M. vulneris, and M. yongonense [49••]. The frequency of isolating MAC members varies geographically with M. intracellulare seen frequently in human patients in Australia and South Africa and M. avium predominating in Europe and the Americas [50]. In immunocompromised humans, such as HIV patients or transplant recipients, MAC is the leading cause of pulmonary and disseminated mycobacteriosis $[15,49 \bullet \bullet]$. However, healthy humans and animals are considered to be rather resistant to develop MAC-related mycobacteriosis.

The species Mycobacterium avium is currently divided into four subspecies including avium (MAA), silvaticum (MAS), hominissuis (MAH), and paratuberculosis (MAP) based on phenotypic peculiarities such as mycobactin J dependency (MAP and MAS) or specific genetic markers that will be further discussed below $[49 \bullet \bullet, 51 \bullet \cdot$. It has to be mentioned that, because of financial or technical constraints, only specialized laboratories can accurately distinguish between MAA, MAH, or novel MAC members, such as $M$. colombiense and M. chimaera. As indicated by its name, the subspecies MAH is frequently recovered from humans and swine. In addition, this ubiquitous environmental saprophyte has a broad host range, and cases of disseminated MAH infection have been described in other mammals, including dogs, cats, cattle, goats, domestic rabbits, free-ranging red deer, African elephants, and horses [52-59].

Remarkable genetic heterogeneity among MAH strains has been elucidated with specific molecular markers including internal transcribed spacer (e.g., sequevars Mav-A and Mav-B), insertion sequences (ISMav6), or multispacer sequence typing (e.g., MST22) [60•, 61•, 62]. Consequently, an association between certain genotypes and increased virulence, ability of long-term persistence and biofilm formation, or host-species predilection is evident.

Assuming that MAP is an obligate pathogen of ruminants and MAA/MAS are obligate pathogens of birds, MAH has been proposed to be the only true environmental subspecies of $M$. avium $[51 \bullet \cdot$. MAP is an obligate intracellular pathogen, especially in ruminant species and is the etiological agent of paratuberculosis, a contagious disease listed by the World Organisation for Animal Health and also known as Johne's disease. This chronic progressive intestinal disease has also been reported in horses, pigs, deer, alpaca, llama, rabbits, free-ranging carnivores, and dogs [52, 63, 64]. The granulomatous gastroenteritis is causing diarrhea, malabsorption, decreased milk production, and wasting $[52,64,65]$. The MAA and $M$. genavense are considered a major bird pathogen, causing avian mycobacteriosis but only occasionally infections and disease in other animals and humans $[51 \bullet \cdot$. In contrast, MAH has only rarely been isolated from tuberculous lesions in birds [66]. Therefore, the common belief that contaminated poultry carcasses or excrements/droppings are a major source of MAC infections for dogs should be dismissed.

In most published canine case reports, the involved M. avium subspecies was not identified [67-76]. However, according to recent studies and unpublished data by authors, MAH appears to be the predominant pathogenic subspecies $[77 \bullet, 78 \bullet, 79 \bullet, 80 \bullet$. Occasionally, mycobacteriosis due to MAP [64] or MAA [81] has been reported in dogs. To date, there are over 43 published cases reporting MAC-related mycobacteriosis in dogs (Table 1); however, there are many more unreported cases particularly in the Miniature Schnauzer and Basset hound breeds. Absence of epidemiological data for a non-notifiable disease, negligible impact of additional case reports, and misdiagnoses are some of the reasons for this underreporting.

As MAH is ubiquitous and dogs are likely confronted with this opportunistic pathogen from an early stage of their life almost daily, it can be stated that the number of clinical infections caused in dogs and humans is extremely low. However, as it is for humans, immunocompromised dogs can develop systemic and life-threatening mycobacteriosis due to MAC infection. And indeed even among the published case reports (43 cases), a breed predilection to MAC infection is evident for Miniature Schnauzers (16 cases) and Basset Hounds (10 cases). Because over a half (60\%) of all published cases are in breeds with a known genetic predisposition, the summary of these cases is heavily influenced by those with a clear breed predisposition. Among the case reports, most affected dogs were young, with the highest risk of developing signs within the first 3 years of age and only rarely in dogs older than 5 years. Weight loss, lethargy, and inappetence were the predominating signs, followed by lymphadenopathy, splenomegaly, and gastrointestinal signs. Other less common clinical signs included spinal pain, paresis, lameness, subcutaneous swellings, and diffuse alopecia. Extensive granulomatous invasion was found in various examined organs including the small and large intestine, spleen, liver, lungs, bone marrow, and various lymph nodes (inguinal, mediastinal, mesenteric, prescapular, submandibular) in most dogs.

While there are many genetic predispositions to infections in humans and animals, few are restricted to very specific organisms like mycobacteria. Hereditary immunodeficiencies in human patients with mycobacteriosis have been associated 


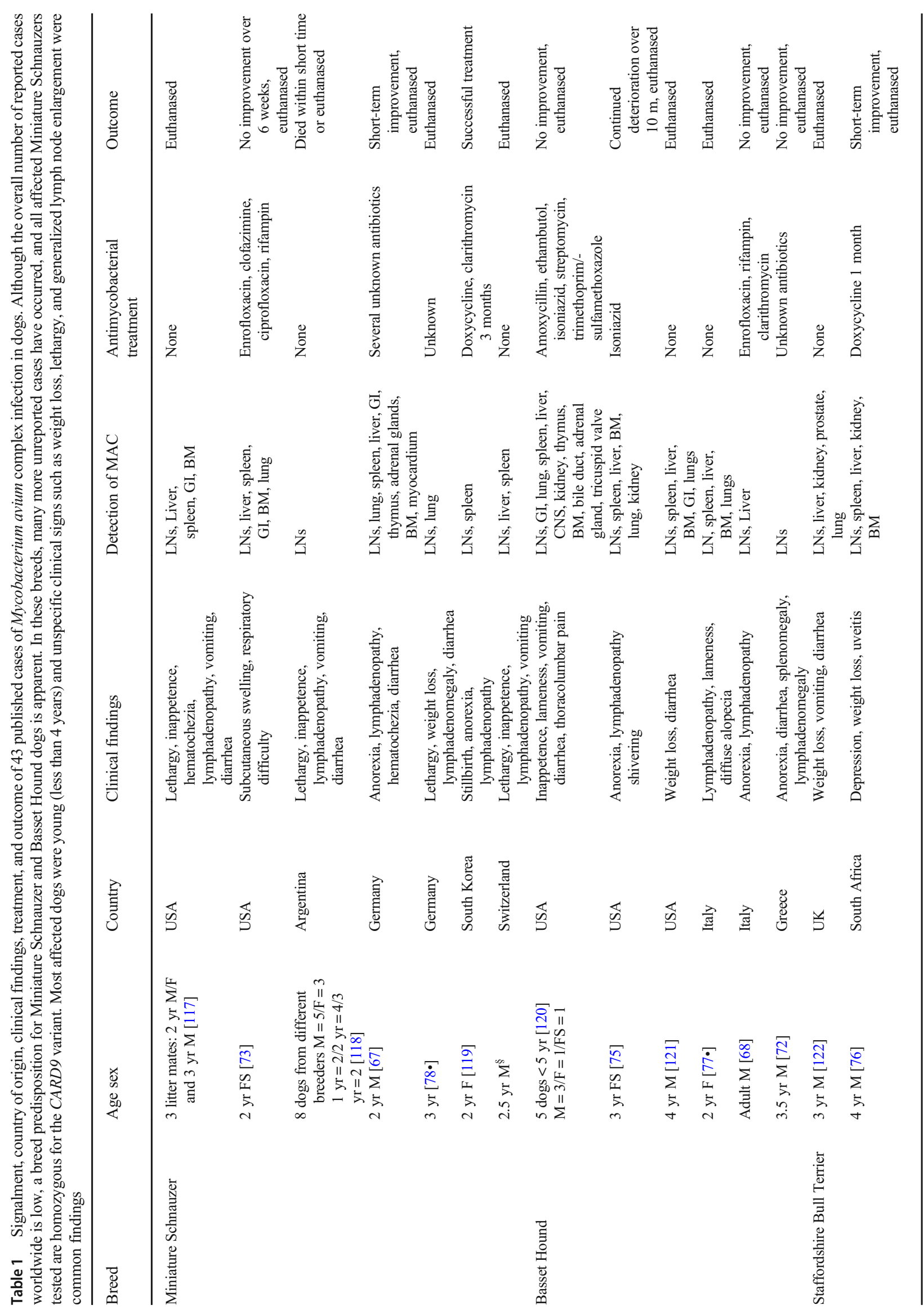




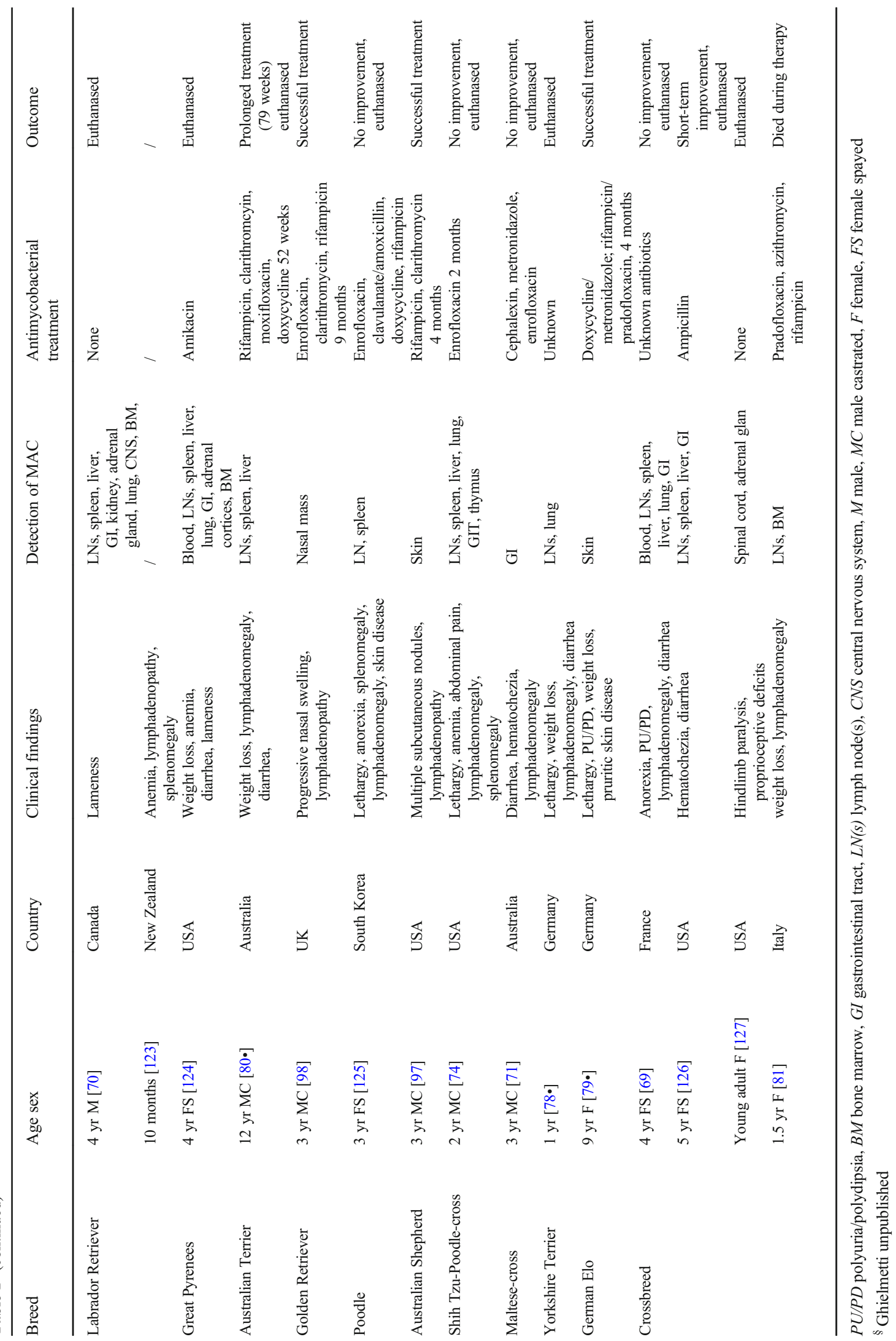


with variants in both subunits of the IFN- $\gamma$ receptor, beta- 1 chain of the interleukin-12 receptor, or the signal transducer and activator of transcription 1 (STAT1), which plays a crucial role in controlling intracellular responses to bacteria and viruses [82-84]. However, acquired immunodeficiencies are far more common than hereditary predisposition. Furthermore, the causative nature of the specific gene defects has been less well-defined. Recently, a single variant in the caspase recruitment domain-containing protein 9 (CARD9) gene has been documented in Miniature Schnauzer dogs [85] (manuscript in preparation UG).

The CARD9 molecule is a multi-functional signaling protein and is essential in autonomous innate host defense against a variety of fungal species, including Candida albicans, Aspergillus fumigatus, or Cryptococcus neoformans and intracellular bacterial pathogens such as Listeria monocytogenes and $M$. tuberculosis $[86,87]$. The CARD9 signaling pathway plays a pivotal role in autonomous innate host defense against M. tuberculosis [86]. Granulocytes from CARD9-deficient mice failed to produce IL-10 after infection and were not able to control bacterial replication, whereas $\mathrm{T}$ cell response appeared unaffected [86]. To date, similar effects of $C A R D 9$ variants in humans have not been observed in association with mycobacterial infections. Genotyping showed that Miniature Schnauzer homozygous for the CARD9 variant gene always developed systemic mycobacteriosis caused by M. avium . This is an autosomal recessively inherited trait, and a common ancestor of diseased dogs has been found dating back to the late 1980s. While over 100 Miniature Schnauzers have been found to have developed mycobacteriosis over the past three decades, a precision medicine approach including screening for this variant offers not only a precise diagnosis but also detection for carriers to avoid the production of any predisposed offspring in the breed. Mycobacterium avium is not the only opportunistic NTM that is present in the environment; and the reason why MAH infections are predominating remains unknown and might suggest a host-MAH-specific interaction.

The other breed with a genetic predisposition to MACassociated mycobacteriosis is the Basset Hound. This unique susceptibility presents similarly but seems to be less common than in Miniature Schnauzers, and the underlying cause still needs to be elucidated. While tuberculosis due to MTBC infections in the gray wolves has been described, mycobacteriosis due to NTM has so far not been reported, further supporting the innate resistance of canidae against MAC except those with hereditary or acquired immunodeficiencies. Inbreeding does not raise the risk of new allele variants, but it can increase homozygosity of deleterious autosomal recessive traits as seen with the CARD9 variant in Miniature Schnauzers [88]. The engagement and collaboration of researchers, veterinary clinicians, and dog breeders are therefore crucial for the further prevention of this fatal infection and to understand the underlying mechanisms of MAH invasion.

\section{Diagnosis and Prevention}

Ante-mortem diagnosis of a mycobacterial infection can be challenging, especially in cases where only internal organs are affected. Tuberculin skin tests (TST) for diagnosis of tuberculosis have been applied in dogs but has been shown to be of unreliable clinical utility and should not be used [20, 21, 89]. Currently, there are no validated commercial in vitro assays such as serological or whole-blood tests that can measure the immune reactivity of infected or sensitized dogs specifically against mycobacteria. With the interferon-gamma (IFN- $\gamma$ ) release assays (IGRA), the amount of released IFN- $\gamma$ after antigen-specific stimulation can be quantified. The IGRA can be performed using purified protein derivative (PPD) from MTBC (e.g., M. tuberculosis or M. bovis), and avian PPD (M. avium) as antigens, or more specific stimulants such as early secretory antigenic target $6 \mathrm{kDa}$ (ESAT-6) and culture filtrate protein $10 \mathrm{kDa}$ (CFP-10). Commercial collection tubes coated on the inner surface with the necessary stimulants enabling immediate exposure of viable lymphocytes to specific mycobacterial antigens are now available [90]. Different IGRAs have been successfully used in domestic dogs and other canidae to detect immunological sensitization to MTBC [20, 90, 91]. Similarly, IGRAs for the early diagnosis of Johne's disease caused by MAP showed promising results in farm ruminants $[65,92,93]$. The ubiquitous nature of MAH impedes the implementation of an IGRA assay for canine $M$. avium detection, as it may merely reflect exposure to MAH and would not be informative about the current infection and disease status of the tested dogs.

Fine needle aspiration or biopsy specimens from cutaneous lesions and enlarged lymph nodes can readily be obtained in veterinary practice. In the presence of acid-fast bacteria after Ziehl-Neelsen staining and/or histopathological finding such as caseating granulomatous lesions, a mycobacterial infection can be suspected. However, the only definitive means to correctly identify the observed mycobacteria is by cultures or molecular methods. Due to the potential zoonotic risk and in cases where treatment is appropriate, it is important to identify the involved Mycobacterium sp. and perform antimicrobial susceptibility testing after mycobacterial isolation. However, mycobacterial cultures should only be performed by established specialized laboratories.

Techniques to identify rapid- and slow-growing mycobacteria depend on the laboratory infrastructure, equipment, expertise, and specimen to be tested. Traditional biochemical tests, specific reverse hybridization-based lineprobe commercial kit assays, sequence analysis of selected housekeeping genes, and MALDI-TOF MS are valid methods currently used alone or in combination. Molecular genetic techniques, in particular specific gene or whole genome sequencing, allow for a better discrimination than traditional culture and biochemical methods, resulting in the recent 
description of a myriad of new species. The 16S rRNA gene, coding for a component of the $30 \mathrm{~S}$ small subunit of the prokaryotic ribosome, is the most common gene used for identification and phylogeny of bacteria [94]. Sequence analysis of the 16S rRNA gene has become a cornerstone of mycobacterial classification and taxonomy because of its discriminatory power and the availability of comprehensive freely accessible databases. However, because of the high genetic similarity of certain closely related mycobacteria, $16 \mathrm{~S}$ rRNA gene analysis does not provide the necessary resolution capacity. For instance, the four subspecies of Mycobacterium avium are characterized by identical 16S rRNA gene sequences.

Beside the fundamental phenotypic features, such as mycobactin J dependency of MAP and MAS, additional markers for the differentiation of MAC species and M. avium subspecies have been described and should be applied. These include insertion sequences (IS), e.g., IS901 present in MAA and MAS, IS900 found in MAP and ISMav6, which is a genetic variant of the original bird-type IS901, and a marker associated with virulent MAH strains [49••]. Another discriminating gene for M. avium subspecies is $h s p 65$, particularly its 3 '-region, which has been shown to contain subspecies-specific signatures [95]. When specifically analyzed, dogs with MAC mycobacteriosis are predominantly infected with MAH.

In Miniature Schnauzer dogs, the increased susceptibility to MAC infection and diagnosis of mycobacteriosis can be simply predicted even prior to exhibiting disease by showing homozygosity for the breed-specific $C A R D 9$ variant by PCR testing. In this regard, the proactive screening of Miniature Schnauzers used in breeding programs is reducing the number of MAC susceptible dogs carrying this deleterious variant from the breed. No DNA test is currently available for testing the genetic susceptibility to MAC infections in Basset Hounds [85].

\section{Management}

Due to the high zoonotic risk of MTBC members, dogs diagnosed with tuberculosis should not be treated and humanely euthanized. Contact to dogs with TB should be restricted and exposed people, particularly those with immunodeficiency and immunosuppression, should be advised to contact their primary care physician and/or infectious disease specialist to undergo appropriate diagnostic investigations and potentially treatment. Although interspecies transmission of NTM has not been unequivocally described, the zoonotic potential of affected animals with any Mycobacterium sp. should not be underestimated. The minimal infective dose of most NTM species for human beings is yet to be determined, and infected dogs expose their potentially immunocompromised owners and other people to a far higher infection pressure even before they are showing obvious clinical signs. Among the members of the MAC, only M. vulneris has been specifically associated with a possible transmission between dogs and humans, as $M$. vulneris was cultured from an infected dog bite wound of a 42-year-old woman [96].

Because of the potential zoonotic risk and increasing interactions between human and companion animals, immunologically compromised people who are in close contact with NTM-infected dogs should be referred to their primary care physicians. According to the available literature, diagnostics and therapy of NTM infections depend on the mycobacterial (sub-) species, localized or systemic disease manifestation, as well as the host defense status. Any treatment attempts should be discouraged in breeds with an immunodeficiency.

Localized or disseminated cutaneous infections such as pyogranulomatous dermatitis and panniculitis with or without systemic clinical signs seem to have a favorable prognosis after prolonged antimicrobial therapy in dogs other than Miniature Schnauzers or Basset Hounds [79•, 97, 98]. Because isolation and susceptibility testing of mycobacteria is usually protracted for slowly growing mycobacteria, initial empiric antimycobacterial therapy is often necessary to impede the spread to adjacent tissue compartments [99]. The combination of antimycobacterial agents effective against slowly growing NTM, such as rifampicin and clarithromycin, combined with newer generation fluoroquinolones, e.g., moxifloxacin or pradofloxacin, has been used in isolated cases $[32 \bullet \bullet, 100]$. Doxycycline, macrolide, or fluoroquinolone as monotherapy is a common practice in veterinary medicine but may well not be effective even in immunocompetent dogs.

The experience from the literature shows that once the disease is disseminated, MAC mycobacteriosis is progressive and affected animals die or have to be euthanized regardless of any treatment attempts.

\section{Infection Sources for Mycobacterium avium}

Because of the ubiquitous nature of MAH in soil and water, different possible transmission routes, the broad host range, unspecific clinical signs, and long incubation period (weeks to months) of the disease, MAC infections in dogs represent epidemiological challenges (Fig. 1). The source and time of infection remain generally unknown and, thus, retrospective contact tracing is impractical. Whether infected animals, especially pets with close contact to their owners, play a role in the epidemiology of human mycobacteriosis caused by M. avium is still to be defined.

Noteworthy, only a low degree of homology between MAH isolates from Japanese human patients and local pigs was observed, whereas isolates from European human patients and from pigs in Japan and Europe were highly similar [53, 61•, 62•, 101, 102]. However, the source and time of MAC infection remains in most human patients and dogs unknown due to the long incubation period until overt disease occurs. Interregional or even international travel is commonly done for show dogs, pet purchases, 


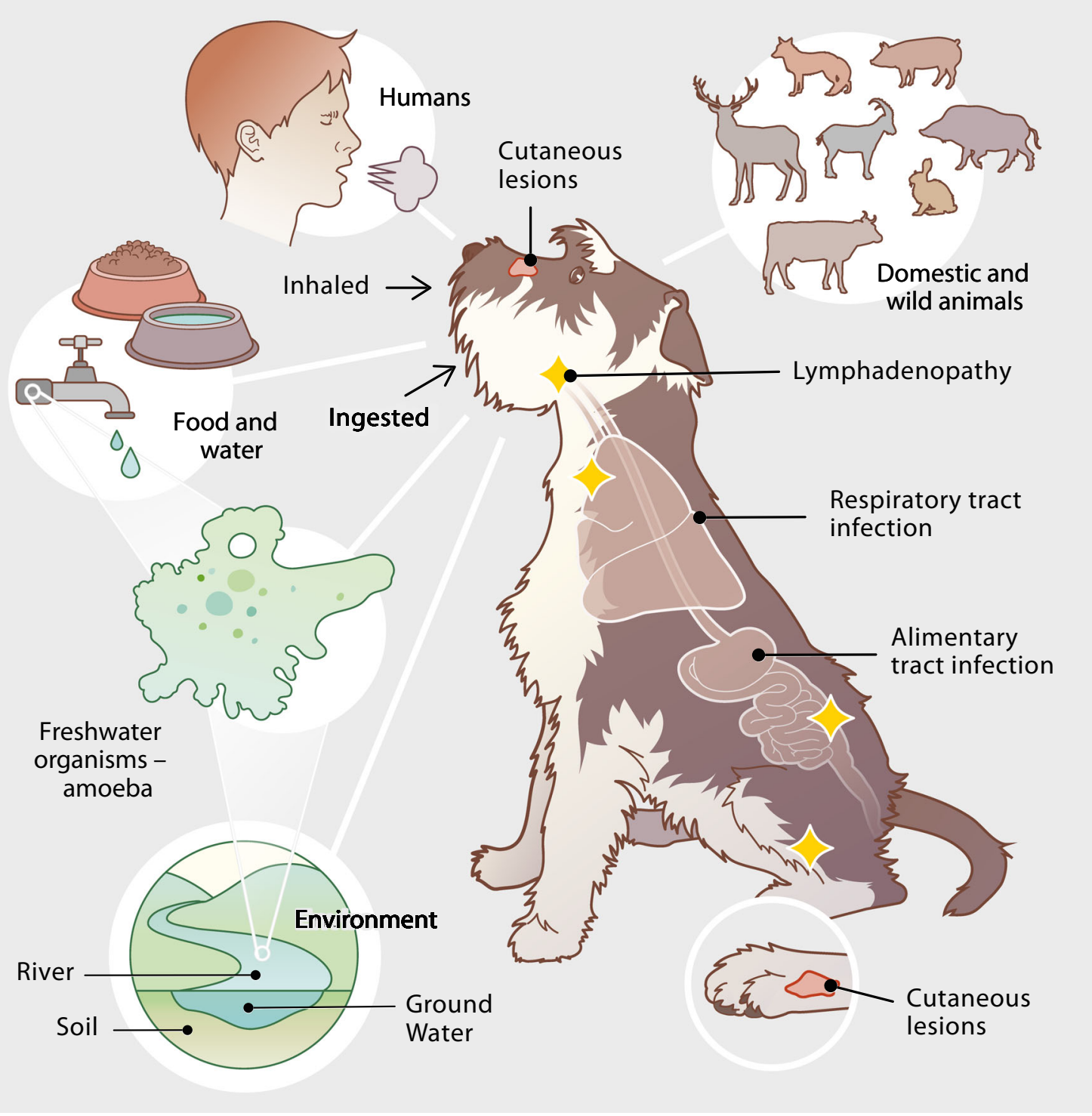

Fig. 1 Infection sources of Mycobacterium avium subsp. hominissuis $(\mathrm{MAH})$ for dogs and common anatomical locations of mycobacteriosis; note frequently disseminated manifestation. Mycobacterium avium subsp. hominissuis is widely distributed in soil, ground- and tap water. While various mammals belong to the host range of MAH and potentially spread the mycobacteria into their living environment, birds are not likely to be a source of infection. Moreover, free-living organisms such as amoebae harbor MAH and may act as vehicles for the mycobacteria. Yellow stars represent the most commonly enlarged lymph nodes

and kitchen tap water [104, 105]. In Germany, MAH was recovered in dust and soil by culturing indoor and outdoor samples. Interestingly, MAH was significantly more often isolated from locations with close human contact such as indoor home dust and biofilms from sanitation facilities compared with countryside samples containing water, biofilm, and soil [106]. The MAC member M. chimaera was found in heater-cooler devices used in cardiac surgery leading to worldwide invasive nosocomial infections in humans $[107,108]$.

Free-living amoebae are common unicellular eukaryotes living in soil, brackish water, and potable water distribution systems [109] including hospital water systems [110]. They feed mainly via phagocytosis and inactivation of ubiquitous bacteria rare or not detectable in bathroom samples from control patients 
and other microorganisms. However, many mycobacteria are known to be resistant against their phagocytosis and are able to reside unharmed and even multiply within the amoebal exocyst [111-114]. Thereby, mycobacteria can persist under adverse environmental conditions and against disinfectants, e.g., chlorine used for reduction of water-borne pathogens $[115,116]$. Therefore, amoebal cysts are probable vehicles for opportunistic pathogens such as MAC, which can rapidly exit the cyst once ingested by mammals or further colonize the patient's environment. These findings suggest marked geographic differences, possibly influences by socio-economic aspects such as water supplies systems, local diets, and cooking habits.

\section{Conclusions}

Mycobacteriosis caused by MAC in an emerging disease in humans and dogs. While acquired immunodeficiencies prevail in human patients, a genetic predisposition to MAC in two breeds is responsible for most reported cases in dogs. Synergistic efforts from microbiologists, clinicians, infectious disease specialists, and breeders applying the One Health approach are necessary to improve our understanding of canine mycobacteriosis and assure animal and human health. Dogs with CARD9 deficiency may prove to be an appropriate animal model to study the host-microbe interactions and efficacy of treatments.

Acknowledgments The authors wish to thank Roger Stephan and Guido Bloemberg for fruitful discussions and proofreading the manuscript. They are grateful to Tara von Grebel for the excellent graphical support.

Funding Information Open access funding provided by University of Zurich. The authors received no financial support for the authorship and publication of this article. The original studies on the molecular and immunological characterizations of the genetic predisposition to mycobacteriosis in Miniature Schnauzers and Basset Hounds were supported by AKC Canine Health Foundation, the American Miniature Schnauzer Club and the National Institutes of Health (OD 010939).

\section{Compliance with Ethical Standards}

Conflict of Interest The authors declare no potential conflicts of interest with respect to the research, authorship, and publication of this article.

Open Access This article is licensed under a Creative Commons Attribution 4.0 International License, which permits use, sharing, adaptation, distribution and reproduction in any medium or format, as long as you give appropriate credit to the original author(s) and the source, provide a link to the Creative Commons licence, and indicate if changes were made. The images or other third party material in this article are included in the article's Creative Commons licence, unless indicated otherwise in a credit line to the material. If material is not included in the article's Creative Commons licence and your intended use is not permitted by statutory regulation or exceeds the permitted use, you will need to obtain permission directly from the copyright holder. To view a copy of this licence, visit http://creativecommons.org/licenses/by/4.0/.

\section{References}

Papers of particular interest, published recently, have been highlighted as:

- Of importance

•- Of major importance

1. Gupta RS, Lo B, Son J. Phylogenomics and comparative genomic studies robustly support division of the genus Mycobacterium into an emended genus Mycobacterium and four novel genera. Front Microbiol. 2018;9:67. https://doi.org/10.3389/fmicb.2018.00067.

2. Tortoli E, Brown-Elliott BA, Chalmers JD, Cirillo DM, Daley CL, Emler S, et al. Same meat, different gravy: ignore the new names of mycobacteria. Eur Respir J. 2019;54(1). https://doi.org/10.1183/ 13993003.00795-2019. The authors invite microbiologists and clinicians to wilfully ignore renaming of clinically important organisms such as nontuberculous mycobacteria.

3. Balish M, Bertaccini A, Blanchard A, Brown D, Browning G, Chalker V, et al. Recommended rejection of the names Malacoplasma gen. nov., Mesomycoplasma gen. nov., Metamycoplasma gen. nov., Metamycoplasmataceae fam. nov., Mycoplasmoidaceae fam. nov., Mycoplasmoidales ord. nov., Mycoplasmoides gen. nov., Mycoplasmopsis gen. nov. [Gupta, Sawnani, Adeolu, Alnajar and Oren 2018] and all proposed species comb. nov. placed therein. Int J Syst Evol Microbiol. 2019;69(11):3650-3653, https://doi.org/10.1099/ijsem.0.003632.

4. Reynolds J, Moyes RB, Breakwell DP. Differential staining of bacteria: acid fast stain. Curr Protoc Microbiol. 2009 Nov;Appendix 3:Appendix 3H, https://doi.org/10.1002/ 9780471729259.mca03hs15.

5. Tortoli E. Microbiological features and clinical relevance of new species of the genus Mycobacterium. Clin Microbiol Rev. 2014 Oct;27(4):727-52. https://doi.org/10.1128/CMR.00035-14.

6. Alcaide F, Amlerova J, Bou G, Ceyssens PJ, Coll P, Corcoran D, et al. How to: identify non-tuberculous Mycobacterium species using MALDI-TOF mass spectrometry. Clin Microbiol Infect. 2018 Jun;24(6):599-603. https://doi.org/10.1016/j.cmi.2017.11. 012.

7. Mediavilla-Gradolph MC, De Toro-Peinado I, Bermudez-Ruiz MP, Garcia-Martinez Mde L, Ortega-Torres M, Montiel QuezelGuerraz N, et al. Use of MALDI-TOF MS for identification of nontuberculous Mycobacterium species isolated from clinical specimens. Biomed Res Int. 2015;2015:854078-6. https://doi. org $/ 10.1155 / 2015 / 854078$.

8. Brites D, Loiseau C, Menardo F, Borrell S, Boniotti MB, Warren $\mathrm{R}$, et al. A new phylogenetic framework for the animal-adapted Mycobacterium tuberculosis complex. Front Microbiol. 2018;9: 2820. https://doi.org/10.3389/fmicb.2018.02820.

9. Deforges L, Boulouis HJ, Thibaud JL, Boulouha L, Sougakoff W, Blot S, et al. First isolation of Mycobacterium microti (Llamatype) from a dog. Vet Microbiol. 2004 Nov 15;103(3-4):249 53. https://doi.org/10.1016/j.vetmic.2004.06.016.

10. O'Halloran C, Hope JC, Dobromylskyj M, Burr P, McDonald K, Rhodes S, et al. An outbreak of tuberculosis due to Mycobacterium bovis infection in a pack of English Foxhounds (2016-2017). Transbound Emerg Dis. 2018 Dec;65(6):1872-84. https://doi.org/10.1111/tbed.12969.

11. Sykes JE, Cannon AB, Norris AJ, Byrne BA, Affolter T, O'Malley MA, et al. Mycobacterium tuberculosis complex infection in a dog. J Vet Intern Med. 2007;21(5):1108-12. https://doi. org/10.1892/0891-6640(2007)21[1108:mtciia]2.0.co;2. 
12. Cousins DV. Mycobacterium bovis infection and control in domestic livestock. Rev Sci Tech. 2001;20(1):71-85. https://doi.org/ 10.20506/rst.20.1.1263.

13. Johansen MD, Herrmann JL, Kremer L. Non-tuberculous mycobacteria and the rise of Mycobacterium abscessus. Nat Rev Microbiol. 2020;18:392-407. https://doi.org/10.1038/s41579020-0331-1.

14. Biet F, Boschiroli ML. Non-tuberculous mycobacterial infections of veterinary relevance. Res Vet Sci. 2014;97(Suppl):S69-77. https://doi.org/10.1016/j.rvsc.2014.08.007.

15. Griffith DE, Aksamit T, Brown-Elliott BA, Catanzaro A, Daley C, Gordin F, et al. An official ATS/IDSA statement: diagnosis, treatment, and prevention of nontuberculous mycobacterial diseases. Am J Respir Crit Care Med. 2007;175(4):367-416. https://doi. org/10.1164/rccm.200604-571ST.

16. Gunn-Moore DA. Feline mycobacterial infections. Vet J. 2014;201(2):230-8. https://doi.org/10.1016/j.tvj1.2014.02.014

17. WHO. Buruli ulcer (Mycobacterium ulcerans infection) [accessed March 1, 2020]. Available from: https://www.who.int/newsroom/fact-sheets/detail/buruli-ulcer-(mycobacterium-ulceransinfection).

18. Johnson MM, Odell JA. Nontuberculous mycobacterial pulmonary infections. J Thorac Dis. 2014;6(3):210-20. https://doi.org/ 10.3978/j.issn.2072-1439.2013.12.24

19. Erwin PC, Bemis DA, McCombs SB, Sheeler LL, Himelright IM, Halford SK, et al. Mycobacterium tuberculosis transmission from human to canine. Emerg Infect Dis. 2004;10(12):2258-10. https:// doi.org/10.3201/eid1012.040094.

20. Parsons SD, Warren RM, Ottenhoff TH, Gey van Pittius NC, van Helden PD. Detection of Mycobacterium tuberculosis infection in dogs in a high-risk setting. Res Vet Sci. 2012;92(3):414-9. https:// doi.org/10.1016/j.rvsc.2011.03.026.

21. Bonovska M, Tzvetkov Y, Najdenski H, Bachvarova Y. PCR for detection of Mycobacterium tuberculosis in experimentally infected dogs. J Vet Med B Infect Dis Vet Public Health. 2005;52(4): 165-70. https://doi.org/10.1111/j.1439-0450.2005.00839.x.

22. Foster ES, Scavelli TD, Greenlee PG, Gilbertson SR. Cutaneous lesion caused by Mycobacterium tuberculosis in a dog. J Am Vet Med Assoc. 1986;188(10):1188-90.

23. Liu S, Weitzman I, Johnson GG. Canine tuberculosis. J Am Vet Med Assoc. 1980;177(2):164-7.

24. Martinho AP, Franco MM, Ribeiro MG, Perrotti IB, Mangia SH, Megid J, et al. Disseminated Mycobacterium tuberculosis infection in a dog. Am J Trop Med Hyg. 2013;88(3):596-600. https:// doi.org/10.4269/ajtmh.12-0332.

25. Saxegaard F, Svenkerud R. A case of canine tuberculosis caused by Mycobacterium tuberculosis. Acta Vet Scand. 1982;23(2): 309-11.

26. Olea-Popelka F, Muwonge A, Perera A, Dean AS, Mumford E, Erlacher-Vindel E, et al. Zoonotic tuberculosis in human beings caused by Mycobacterium bovis-a call for action. Lancet Infect Dis. 2017;17(1):E21-E5. https://doi.org/10.1016/S14733099(16)30139-6.

27. Ellis MD, Davies S, McCandlish IA, Monies R, Jahans K, de la Rua-Domenech R. Mycobacterium bovis infection in a dog. Vet Rec. 2006;159(2):46-8. https://doi.org/10.1136/vr.159.2.46.

28. Gay G, Burbidge HM, Bennett P, Fenwick SG, Dupont C, Murray A, et al. Pulmonary Mycobacterium bovis infection in a dog. N Z Vet J. 2000;48(3):78-81. https://doi.org/10.1080/00480169.2000. 36164.

29. Rocha VC, Figueiredo SC, Rosales CA, Porto CD, Sequeira JL, Neto JS, et al. Infection by Mycobacterium bovis in a dog from Brazil. Braz J Microbiol. 2017;48(1):109-12. https://doi.org/10. 1016/j.bjm.2016.09.001.

30. Lutze-Wallace C, Berlie-Surujballi G, Barbeau Y, Bergeson D. Strain typing of Mycobacterium bovis from a 1978 case of tuberculosis in a wolf (Canis lupis) from Manitoba. Can Vet J. 2005;46(6):502.

31. Orlowska B, Augustynowicz-Kopec E, Krajewska M, Zabost A, Welz M, Kaczor S, et al. Mycobacterium caprae transmission to free-living grey wolves (Canis lupus) in the Bieszczady Mountains in Southern Poland. Eur J Wildl Res. 2017;63(1). https://doi.org/10.1007/s10344-017-1079-4.

32.• Malik R, Smits B, Reppas G, Laprie C, O’Brien C, Fyfe J. Ulcerated and nonulcerated nontuberculous cutaneous mycobacterial granulomas in cats and dogs. Vet Dermatol. 2013;24(1):146-53 e32-3. https://doi.org/10.1111/j.1365-3164.2012.01104.x. This review concentrates on noncultivable mycobacterial species that cause granulomas of the skin and subcutis in dogs and cats, current noninvasive identification methods and treatment possibilities.

33. Conceicao LG, Acha LM, Borges AS, Assis FG, Loures FH. Fonseca e Silva F. epidemiology, clinical signs, histopathology and molecular characterization of canine leproid granuloma: a retrospective study of cases from Brazil. Vet Dermatol. 2011;22(3):249-56. https://doi.org/10.1111/j.1365-3164.2010. 00934.x.

34. Foley JE, Borjesson D, Gross TL, Rand C, Needham M, Poland A. Clinical, microscopic, and molecular aspects of canine leproid granuloma in the United States. Vet Pathol. 2002;39(2):234-9. https://doi.org/10.1354/vp.39-2-234.

35. Djouaka R, Zeukeng F, Bigoga JD, Kakou-Ngazoa SE, Akoton R, Tchigossou $G$, et al. Domestic animals infected with Mycobacterium ulcerans-implications for transmission to humans. PLoS Negl Trop Dis. 2018;12(7):e0006572. https://doi. org/10.1371/journal.pntd.0006572.

36. O'Brien CR, McMillan E, Harris O, O'Brien DP, Lavender CJ, Globan M, et al. Localised Mycobacterium ulcerans infection in four dogs. Aust Vet J. 2011;89(12):506-10. https://doi.org/10. 1111/j.1751-0813.2011.00850.x.

37. Malik R, Shaw SE, Griffin C, Stanley B, Burrows AK, Bryden SL, et al. Infections of the subcutis and skin of dogs caused by rapidly growing mycobacteria. J Small Anim Pract. 2004;45(10): 485-94. https://doi.org/10.1111/j.1748-5827.2004.tb00193.x.

38. Krimer PM, Phillips KM, Miller DM, Sanchez S. Panniculitis attributable to Mycobacterium goodii in an immunocompetent dog in Georgia. J Am Vet Med Assoc. 2010;237(9):1056-9. https://doi.org/10.2460/javma.237.9.1056.

39. Fox LE, Kunkle GA, Homer BL, Manella C, Thompson JP. Disseminated subcutaneous Mycobacterium fortuitum infection in a dog. J Am Vet Med Assoc. 1995;206(1):53-5.

40. Jang SS, Hirsh DC. Rapidly growing members of the genus Mycobacterium affecting dogs and cats. J Am Anim Hosp Assoc. 2002;38(3):217-20. https://doi.org/10.5326/0380217.

41. Timm K, Welle M, Friedel U, Gunn-Moore D, Peterhans S. Mycobacterium nebraskense infection in a dog in Switzerland with disseminated skin lesions. Vet Dermatol. 2019;30(3):262e80. https://doi.org/10.1111/vde.12739.

42. Irwin PJ, Whithear K, Lavelle RB, Parry BW. Acute bronchopneumonia associated with Mycobacterium fortuitum infection in a dog. Aust Vet J. 2000;78(4):254-7. https://doi.org/10.1111/ j.1751-0813.2000.tb11748.x.

43. Jang SS, Eckhaus MA, Saunders G. Pulmonary Mycobacterium fortuitum infection in a dog. J Am Vet Med Assoc. 1984;184(1): 96-8.

44. Leissinger MK, Garber JB, Fowlkes N, Grooters AM, Royal AB, Gaunt SD. Mycobacterium fortuitum lipoid pneumonia in a dog. Vet Pathol. 2015;52(2):356-9. https://doi.org/10.1177/ 0300985814531497.

45. Murai A, Maruyama S, Nagata M, Yuki M. Mastitis caused by Mycobacterium kansasii infection in a dog. Vet Clin Pathol. 2013;42(3):377-81. https://doi.org/10.1111/vcp.12056. 
46. Pressler BM, Hardie EM, Pitulle C, Hopwood RM, Sontakke S, Breitschwerdt EB. Isolation and identification of Mycobacterium kansasii from pleural fluid of a dog with persistent pleural effusion. J Am Vet Med Assoc. 2002;220(9):1336-40, 13-4. https:// doi.org/10.2460/javma.2002.220.1336.

47. Grooters AM, Couto CG, Andrews JM, Johnson SE, Kowalski JJ, Esplin RB. Systemic Mycobacterium smegmatis infection in a dog. J Am Vet Med Assoc. 1995;206(2):200-2.

48. Kiehn TE, Hoefer H, Bottger EC, Ross R, Wong M, Edwards F, et al. Mycobacterium genavense infections in pet animals. J Clin Microbiol. 1996;34(7):1840-2.

49.• van Ingen J, Turenne CY, Tortoli E, Wallace RJ Jr, Brown-Elliott BA. A definition of the Mycobacterium avium complex for taxonomical and clinical purposes, a review. Int J Syst Evol Microbiol. 2018;68(11):3666-77. https://doi.org/10.1099/ijsem.0.003026. On the basis of literature review and phylogenetic analyses, the authors propose to define the MAC as a grouping of slowgrowing mycobacteria that currently consists of 12 validly published species.

50. Hoefsloot W, van Ingen J, Andrejak C, Angeby K, Bauriaud R, Bemer $\mathrm{P}$, et al. The geographic diversity of nontuberculous mycobacteria isolated from pulmonary samples: an NTM-NET collaborative study. Eur Respir J. 2013;42(6):1604-13. https:// doi.org/10.1183/09031936.00149212.

51.• Turenne CY, Wallace R Jr, Behr MA. Mycobacterium avium in the postgenomic era. Clin Microbiol Rev. 2007;20(2):205-29. https://doi.org/10.1128/CMR.00036-06. The distinction between environmental and pathogenic subsets of $M$. avium is discussed, including review of recent comparative genome analyses, current genetic markers and diagnostic implications.

52. Glawischnig W, Steineck T, Spergser J. Infections caused by Mycobacterium avium subspecies avium, hominissuis, and paratuberculosis in free-ranging red deer (Cervus elaphus hippelaphus) in Austria, 2001-2004. J Wildl Dis. 2006;42(4): 724-31. https://doi.org/10.7589/0090-3558-42.4.724.

53. Johansen TB, Olsen I, Jensen MR, Dahle UR, Holstad G, Djonne B. New probes used for ISI245 and ISI311 restriction fragment length polymorphism of Mycobacterium avium subsp. avium and Mycobacterium avium subsp. hominissuis isolates of human and animal origin in Norway. BMC Microbiol. 2007;5:7. https://doi. org/10.1186/1471-2180-7-14.

54. Klotz D, Barth SA, Baumgartner W, Hewicker-Trautwein M. Mycobacterium avium subsp. hominissuis infection in a domestic rabbit, Germany. Emerg Infect Dis. 2018;24(3):596-8. https://doi. org/10.3201/eid2403.171692.

55. Kriz P, Jahn P, Bezdekova B, Blahutkova M, Mrlik V, Slana I, et al. Mycobacterium avium subsp. hominissuis infection in horses. Emerg Infect Dis. 2010;16(8):1328-9.

56. Madarame H, Saito M, Ogihara K, Ochiai H, Oba M, Omatsu T, et al. Mycobacterium avium subsp. hominissuis menigoencephalitis in a cat. Vet Microbiol. 2017;204:43-5. https://doi.org/10.1016/j.vetmic.2017.04.008.

57. Schinkothe J, Mobius P, Kohler H, Liebler-Tenorio EM. Experimental infection of goats with Mycobacterium avium subsp. hominissuis: a model for comparative tuberculosis research. J Comp Pathol. 2016;155(2-3):218-30. https://doi.org/ 10.1016/j.jcpa.2016.06.008.

58. Wellenberg GJ, de Haas PE, van Ingen J, van Soolingen D, Visser IJ. Multiple strains of Mycobacterium avium subspecies hominissuis infections associated with aborted fetuses and wasting in pigs. Vet Rec. 2010;167(12):451-4. https://doi.org/10.1136/vr. c4274.

59. Wenker C, Wyss F, Hoby S, Ghielmetti G, Friedel U, Gurtner C, et al., editors. Non-tuberculous mycobacterial lung infection in an african elephant (Loxodonta africana) and a greater one-horned rhinoceros (Rhinoceros unicornis) caused by Mycobacterium avium ssp. hominissuis and Mycobacterium nebraskense and the reaction to ante- and postmortem tests. Proceedings of the American Association of Zoo Veterinarians (AAZV); 2018.

60. Bruffaerts N, Vluggen C, Roupie V, Duytschaever L, Van den Poel C, Denoel J, et al. Virulence and immunogenicity of genetically defined human and porcine isolates of $M$. avium subsp. hominissuis in an experimental mouse infection. PLoS One. 2017;12(2):e0171895. https://doi.org/10.1371/journal.pone. 0171895. Based on comparative genome analysis and using a mouse model, a striking link of virulence between porcine and human MAH isolates with the same multisequence type and no spacial correlation was observed.

61. Ichikawa K, van Ingen J, Koh WJ, Wagner D, Salfinger M, Inagaki T, et al. Genetic diversity of clinical Mycobacterium avium subsp. hominissuis and Mycobacterium intracellulare isolates causing pulmonary diseases recovered from different geographical regions. Infect Genet Evol. 2015;36:250-5. https://doi. org/10.1016/j.meegid.2015.09.029. The authors indicate that strains of $M$. avium subsp. hominissuis exhibit geographical differences in genetic diversity and imply that MAC strains may have different sources, routes of transmission and perhaps clinical manifestations.

62. Iwamoto T, Nakajima C, Nishiuchi Y, Kato T, Yoshida S, Nakanishi N, et al. Genetic diversity of Mycobacterium avium subsp. hominissuis strains isolated from humans, pigs, and human living environment. Infect Genet Evol. 2012;12(4):846-52. https://doi.org/10.1016/j.meegid.2011.06.018.

63. Garcia $\mathrm{AB}$, Shalloo L. Invited review: the economic impact and control of paratuberculosis in cattle. J Dairy Sci. 2015;98(8): 5019-39. https://doi.org/10.3168/jds.2014-9241.

64. Miller MA, Davey SC, Van Helden LS, Kettner F, May SM, Last $\mathrm{R}$, et al. Paratuberculosis in a domestic dog in South Africa. J S Afr Vet Assoc. 2017;88:e1-5. https://doi.org/10.4102/jsava. v88i0.1441.

65. Souriau A, Freret S, Foret B, Willemsen PTJ, Bakker D, Guilloteau LA. Identification of new antigen candidates for the early diagnosis of Mycobacterium avium subsp. paratuberculosis infection in goats. Res Vet Sci. 2017;115:278-87. https://doi.org/ 10.1016/j.rvsc.2017.05.025.

66. Shitaye EJ, Grymova V, Grym M, Halouzka R, Horvathova A, Moravkova M, et al. Mycobacterium avium subsp. hominissuis infection in a pet parrot. Emerg Infect Dis. 2009;15(4):617-9. https://doi.org/10.3201/eid1504.081003.

67. Bauer N, Burkhardt S, Kirsch A, Weiss R, Moritz A, Baumgaertner W. Lymphadenopathy and diarrhea in a Miniature Schnauzer. Vet Clin Pathol. 2002;31(2):61-4. https:// doi.org/10.1111/j.1939-165x.2002.tb00281.x.

68. Cucchi E, Bernini S, Chinosi S, Mazzocchi D, Vicini B, Bertazzolo W. Mycobacterium avium complex infection in a dog. Veterinaria. 2009;23:59-63.

69. Etienne CL, Granat F, Trumel C, Raymond-Letron I, Lucas MN, Boucraut-Baralon C, et al. A mycobacterial coinfection in a dog suspected on blood smear. Vet Clin Pathol. 2013;42(4):516-21. https://doi.org/10.1111/vcp.12088.

70. Friend SC, Russell EG, Hartley WJ, Everist P. Infection of a dog with Mycobacterium avium serotype II. Vet Pathol. 1979;16(3): 381-4. https://doi.org/10.1177/030098587901600312.

71. Horn B, Forshaw D, Cousins D, Irwin PJ. Disseminated Mycobacterium avium infection in a dog with chronic diarrhoea. Aust Vet J. 2000;78(5):320-5. https://doi.org/10.1111/j.17510813.2000.tb11781.x.

72. Kontos V, Papadogiannakis EI, Mantziaras G, Styliara M, Kanavaki S. A case of disseminated Mycobacterium avium infection in a dog in Greece. Case Rep Vet Med. 2014;2014:1-3. https://doi.org/10.1155/2014/597847. 
73. Miller MA, Greene CE, Brix AE. Disseminated Mycobacterium avium-intracellulare complex infection in a Miniature Schnauzer. J Am Anim Hosp Assoc. 1995;31(3):213-6. https://doi.org/10. 5326/15473317-31-3-213.

74. O'Toole D, Tharp S, Thomsen BV, Tan E, Payeur JB. Fatal mycobacteriosis with hepatosplenomegaly in a young dog due to Mycobacterium avium. J Vet Diagn Investig. 2005:, https:// doi.org/10.1177/104063870501700220, 17, 200, 204.

75. Shackelford CC, Reed WM. Disseminated Mycobacterium avium infection in a dog. J Vet Diagn Investig. 1989;1(3):273-5. https:// doi.org/10.1177/104063878900100319.

76. Zeiss CJ, Jardine J, Huchzermeyer H. A case of disseminated tuberculosis in a dog caused by Mycobacterium-aviumintracellulare. J Am Anim Hosp Assoc. 1994;30(5):419-24.

77. Campora L, Corazza M, Zullino C, Ebani VV, Abramo F. Mycobacterium avium subspecies hominissuis disseminated infection in a Basset Hound dog. J Vet Diagn Investig. 2011;23(5):1083-7. https://doi.org/10.1177/1040638711418616. A case of disseminated MAH infection in a dog from an American lineage of Basset Hounds is described in Italy. Anamnesis suggests that the dog was immunocompromised.

78. Haist V, Seehusen F, Moser I, Hotzel H, Deschl U, Baumgartner $\mathrm{W}$, et al. Mycobacterium avium subsp. hominissuis infection in 2 pet dogs, Germany. Emerg Infect Dis. 2008;14(6):988-90. https:// doi.org/10.3201/eid1406.071463. The authors report disseminated MAH infection in 2 young dogs from Germany, a 3-year-old miniature schnauzer and a 1-year-old Yorkshire terrier.

79. Hobi S, Bettenay S, Majzoub M, Mueller R, Moser I. Mycobacterium avium subspecies hominissuis infection in a dog from Germany with multifocal alopecia, exfoliative dermatitis, hypercalcaemia and subsequent sebaceous atrophy. 2015;Vet Rec Case Rep, https://doi.org/10.1136/vetreccr-2014-000168. A peculiar case of MAH infection in a dog from Germany with multifocal alopecia, exfoliative dermatitis, and hypercalcaemia is reported.

80. Lam A, Foster D, Martin P, Spielman D, Chee H, Strong M, et al. Treatment of Mycobacterium avium infection in a dog. Aust Vet Pract. 2012;42(2):234-9.

81. Armas F, Furlanello T, Camperio C, Trotta M, Novari G, Marianelli C. Molecular characterization and drug susceptibility profile of a Mycobacterium avium subspecies avium isolate from a dog with disseminated infection. J Med Microbiol. 2016;65(4): 278-85. https://doi.org/10.1099/jmm.0.000221.

82. Haverkamp MH, van de Vosse E, van Dissel JT. Nontuberculous mycobacterial infections in children with inborn errors of the immune system. J Inf Secur. 2014;68:S134-S50. https://doi.org/10. 1016/j.jinf.2013.09.024.

83. Mortaz E, Moloudizargari M, Varahram M, Movassaghi M, Garssen J, Dizagie MK, et al. What immunological defects predispose to non-tuberculosis mycobacterial infections? Iran $\mathrm{J}$ Allerg Asthma Immunol. 2018;17(2):100-9.

84. Wu UI, Holland SM. Host susceptibility to non-tuberculous mycobacterial infections. Lancet Infect Dis. 2015;15(8):968-80. https://doi.org/10.1016/S1473-3099(15)00089-4.

85. Mizukami K, Dorsey-Oresto A, Raj K, Erings A, Furrow E, Johnsom GS, et al., editors. A codon deletion in CARD9 gene causes increased susceptibility to Mycobacterium avium complex in Miniature Schnauzer dogs. 9th International Conference on Canine and Feline Genetics and Genomics; 2017; Landmark Center, Saint Paul, Minnesota.

86. Dorhoi A, Desel C, Yeremeev V, Pradl L, Brinkmann V, Mollenkopf HJ, et al. The adaptor molecule CARD9 is essential for tuberculosis control. J Exp Med. 2010;207(4):777-92. https:// doi.org/10.1084/jem.20090067.
87. Drummond RA, Franco LM, Lionakis MS. Human CARD9: a critical molecule of fungal immune surveillance. Front Immunol. 2018;9:1836. https://doi.org/10.3389/fimmu.2018.01836.

88. Robinson JA, Raikkonen J, Vucetich LM, Vucetich JA, Peterson RO, Lohmueller KE, et al. Genomic signatures of extensive inbreeding in Isle Royale wolves, a population on the threshold of extinction. Sci Adv. 2019;5(5):eaau0757. https://doi.org/10.1126/ sciadv.aau0757.

89. Francis J. Tuberculosis in the dog, with special reference to experimental bronchogenic tuberculosis. Am Rev Tuberc. 1956;73(5): 748-63. https://doi.org/10.1164/artpd.1956.73.5.748.

90. Higgitt RL, Schalkwyk OLV, de Klerk-Lorist LM, Buss PE, Caldwell $\mathrm{P}$, Rossouw L, et al. An interferon gamma release assay for the detection of immune sensitization to Mycobacterium bovis in African wild dogs (Lycaon Pictus). J Wildl Dis. 2019;55(3): 529-36. https://doi.org/10.7589/2018-03-089.

91. O'Halloran C, Hope JC, Dobromylskyj M, Burr P, McDonald K, Rhodes S, et al. An outbreak of tuberculosis due to Mycobacterium bovis infection in a pack of English Foxhounds (2016-2017). Transbound Emerg Dis. 2018;65(6):1872-84. https://doi.org/10.1111/tbed.12969.

92. Holbert S, Branger M, Souriau A, Lamoureux B, Ganneau C, Richard G, et al. Interferon gamma response to Mycobacterium avium subsp. paratuberculosis specific lipopentapeptide antigen L5P in cattle. Res Vet Sci. 2015;102:118-21. https://doi.org/10. 1016/j.rvsc.2015.07.017.

93. Stabel JR, Whitlock RH. An evaluation of a modified interferongamma assay for the detection of paratuberculosis in dairy herds. Vet Immunol Immunopathol. 2001;79(1-2):69-81. https://doi. org/10.1016/s0165-2427(01)00253-7.

94. Janda JM, Abbott SL. 16S rRNA gene sequencing for bacterial identification in the diagnostic laboratory: pluses, perils, and pitfalls. J Clin Microbiol. 2007;45(9):2761-4. https://doi.org/10. 1128/JCM.01228-07.

95. Turenne CY, Semret M, Cousins DV, Collins DM, Behr MA. Sequencing of hsp65 distinguishes among subsets of the Mycobacterium avium complex. J Clin Microbiol. 2006;44(2): 433-40. https://doi.org/10.1128/JCM.44.2.433-440.2006.

96. van Ingen J, Boeree MJ, Kosters K, Wieland A, Tortoli E, Dekhuijzen PN, et al. Proposal to elevate Mycobacterium avium complex ITS sequevar MAC-Q to Mycobacterium vulneris sp. nov. Int J Syst Evol Microbiol. 2009;59(Pt 9):2277-82. https:// doi.org/10.1099/ijs.0.008854-0.

97. Ramos SJ, Woodward MC, Wakamatsu N, Bolin SR, Friedman ML. Cutaneous manifestation of Mycobacterium avium complex infection in an Australian shepherd dog. Vet Rec Case Rep. 2019. https://doi.org/10.1136/vetreccr-2019-000934.

98. Sharp E, Taylor S, O'Halloran C. Unusual presentation of canine Mycobacterium avium infection. Vet Rec. 2019;184(26):800. https://doi.org/10.1136/vr.105311.

99. Niederhauser S, Klauser L, Bolliger J, Friedel U, Schmitt S, Ruetten M, et al. First report of nodular skin lesions caused by Mycobacterium nebraskense in a 9-year-old cat. JFMS Open Rep. 2018;4(2):2055116918792685. https://doi.org/10.1177/ 2055116918792685

100. Greene C, Sykes J. In: Infectious diseases of the dog and cat. Infections caused by slow-growing mycobacteria. Fourth ed. St. Louis: Elsevier; 2012. p. 495-521.

101. Uchiya K, Tomida S, Nakagawa T, Asahi S, Nikai T, Ogawa K. Comparative genome analyses of Mycobacterium avium reveal genomic features of its subspecies and strains that cause progression of pulmonary disease. Sci Rep. 2017;3:7. https://doi.org/10. 1038/Srep39750.

102. Yano H, Iwamoto T, Nishiuchi Y, Nakajima C, Starkova DA, Mokrousov I, et al. Population structure and local adaptation of MAC lung disease agent Mycobacterium avium subsp. 
hominissuis. Genom Biol Evol. 2017;9(9):2403-17. https://oi. org/10.1093/gbe/evx183.

103. Feazel LM, Baumgartner LK, Peterson KL, Frank DN, Harris JK, Pace NR. Opportunistic pathogens enriched in showerhead biofilms. Proc Natl Acad Sci U S A. 2009;106(38):16393-9. https://doi.org/10.1073/pnas.0908446106.

104. Nishiuchi Y, Maekura R, Kitada S, Tamaru A, Taguri T, Kira Y, et al. The recovery of Mycobacterium avium-intracellulare complex (MAC) from the residential bathrooms of patients with pulmonary MAC. Clin Infect Dis. 2007;45(3):347-51. https://doi. org/10.1086/519383.

105. Ichijo T, Izumi Y, Nakamoto S, Yamaguchi N, Nasu M. Distribution and respiratory activity of mycobacteria in household water system of healthy volunteers in Japan. PLoS One. 2014;28: 9(10). https://doi.org/10.1371/journal.pone.0110554.

106. Lahiri A, Kneisel J, Kloster I, Kamal E, Lewin A. Abundance of Mycobacterium avium ssp. hominissuis in soil and dust in Germany - implications for the infection route. Lett Appl Microbiol. 2014;59(1):65-70. https://doi.org/10.1111/lam.12243.

107. Sommerstein R, Hasse B, Marschall J, Sax H, Genoni M, Schlegel $\mathrm{M}$, et al. Global health estimate of invasive Mycobacterium chimaera infections associated with heater-cooler devices in cardiac surgery. Emerg Infect Dis. 2018;24(3):576-8. https://doi.org/ 10.3201/eid2403.171554.

108. Sommerstein R, Ruegg C, Kohler P, Bloemberg G, Kuster SP, Sax $\mathrm{H}$. Transmission of Mycobacterium chimaera from heater-cooler units during cardiac surgery despite an ultraclean air ventilation system. Emerg Infect Dis. 2016;22(6):1008-13. https://doi.org/10. 3201/eid2206.160045.

109. Hoffmann R, Michel R. Distribution of free-living amoebae (FLA) during preparation and supply of drinking water. Int J Hyg Environ Health. 2001;203(3):215-9. https://doi.org/10. 1078/S1438-4639(04)70031-0.

110. Rohr U, Weber S, Michel R, Selenka F, Wilhelm M. Comparison of free-living amoebae in hot water systems of hospitals with isolates from moist sanitary areas by identifying genera and determining temperature tolerance. Appl Environ Microbiol. 1998;64(5):1822-4.

111. Ben Salah I, Drancourt M. Surviving within the amoebal exocyst: the Mycobacterium avium complex paradigm. BMC Microbiol. 2010;1:10. https://doi.org/10.1186/1471-2180-10-99.

112. Delafont V, Mougari F, Cambau E, Joyeux M, Bouchon D, Hechard Y, et al. First evidence of amoebae-mycobacteria association in drinking water network. Environ Sci Technol. 2014;48(20):11872-82. https://doi.org/10.1021/es5036255.

113. Ovrutsky AR, Chan ED, Kartalija M, Bai X, Jackson M, Gibbs S, et al. Cooccurrence of free-living amoebae and nontuberculous mycobacteria in hospital water networks, and preferential growth of Mycobacterium avium in Acanthamoeba lenticulata. Appl Environ Microbiol. 2013;79(10):3185-92. https://doi.org/10. 1128/AEM.03823-12.

114. Steinert M, Birkness K, White E, Fields B, Quinn F. Mycobacterium avium bacilli grow saprozoically in coculture with Acanthamoeba polyphaga and survive within cyst walls. Appl Environ Microbiol. 1998;64(6):2256-61.

115. Harriff M, Bermudez LE. Environmental amoebae and mycobacterial pathogenesis. Mol Epidemiol Microorg. 2009;465:433-42. https://doi.org/10.1007/978-1-59745-207-6_28.

116. Vaerewijck MJ, Huys G, Palomino JC, Swings J, Portaels F. Mycobacteria in drinking water distribution systems: ecology and significance for human health. FEMS Microbiol Rev. 2005;29(5):911-34. https://doi.org/10.1016/j.femsre.2005.02. 001.

117. Eggers JS, Parker GA, Braaf HA, Mense MG. Disseminated Mycobacterium avium infection in three Miniature Schnauzer litter mates. J Vet Diagn Investig. 1997;9(4):424-7. https://doi.org/ 10.1177/104063879700900416.

118. Barandiaran S, Martinez Vivot M, Falzoni E, Marfil MJ, Perez Tort G, Rovatti P, et al. Mycobacterioses in dogs and cats from Buenos Aires. Argentina J Vet Diagn Invest. 2017;29(5):729-32. https://doi.org/10.1177/1040638717713795.

119. Han JI, Kang HM, Jang HJ, Noh S, Kang JH, Chang DW, et al. What is your diagnosis? Lymph node aspirates from a dog with stillbirth. Vet Clin Pathol. 2013;42(3):391-2. https://doi.org/10. 1111/vcp.12053.

120. Carpenter JL, Myers AM, Conner MW, Schelling SH, Kennedy FA, Reimann KA. Tuberculosis in five Basset Hounds. J Am Vet Med Assoc. 1988;192(11):1563-8.

121. Walsh KM, Losco PE. Canine mycobacteriosis - a case-report. J Am Anim Hosp Assoc. 1984;20(2):295-9.

122. Gow AG, Gow DJ. Disseminated Mycobacterium avium complex infection in a dog. Vet Rec. 2008;162(18):594-5. https://doi.org/ 10.1136/vr.162.18.594.

123. Black M. Review of diagnostic cases-July to September 1997. Surveillance. 1997;24(4).

124. Naughton JF, Mealey KL, Wardrop KJ, Oaks JL, Bradway DS. Systemic Mycobacterium avium infection in a dog diagnosed by polymerase chain reaction analysis of buffy coat. J Am Anim Hosp Assoc. 2005;41(2):128-32. https://doi.org/10.5326/ 0410128.

125. Kim MC, Kim J, Kang W, Jang Y, Kim Y. Systemic infection of Mycobacterium avium subspecies hominissuis and fungus in a pet dog. J Vet Med Sci. 2016;78(1):157-60. https://doi.org/10.1292/ jvms.15-0285.

126. Beaumont PR, Jezykt PF, Haskins ME. Mycobacterium avium infection in a dog. J Small Anim Pract. 1981;22:91-7.

127. Kim DY, Cho DY, Newton JC, Gerdes J, Richter E. Granulomatous myelitis due to Mycobacterium avium in a dog. Vet Pathol. 1994; 31(4):491-493. https://doi.org/10.1177/ 030098589403100418 .

Publisher's Note Springer Nature remains neutral with regard to jurisdictional claims in published maps and institutional affiliations. 